\section{CoHest} published online only. To view please visit the journal online (http://dx.doi.org/10.1136/ thoraxjnl-2014-205344)

\section{Correspondence to} Prof Vincenzo Ambrogi, Department of Thoracic Surgery, Policlinico Tor Vergata University, Viale Oxford 81, Rome 00133, Italy; ambrogi@med.uniroma2.it

Received 27 February 2014 Revised 4 March 2014 Accepted 5 March 2014 Published Online First 1 April 2014

\title{
Piero della Francesca's coral pendants: the hidden bronchial anatomy
}

\author{
Vincenzo Ambrogi
}

During the Renaissance, painters frequently used to hide human anatomies inside their artworks. Piero della Francesca (1415-1492) in two paintings represents the infant Jesus with a necklace of coral beads, symbol of beauty and tool for protection against illness or sudden death. Interestingly, the shape of both coral pendants follows a scheme similar to the primary and secondary divisions of the lower respiratory system with the trachea, the main and the lobar bronchi. The numerous and surprising analogies between the coral and the true anatomy make consistent the hypothesis of the bronchial tree hidden in Piero della Francesca's coral pendants.

Piero della Francesca's interests extended beyond figurative art, and included arithmetic, algebra and geometry as well as anatomy and biology. ${ }^{1}$ In two of his most well known masterpieces: the Pala Montefeltro (see online figure 1(2) in supplementary file) and the Madonna di Senigallia (see online figure 2(2) in supplementary file), the infant Jesus wears a necklace of coral beads with a small coral branch lying on his chest.

In the former, the coral depicts the bronchial tree from a posterior aspect (figure 1A), whereas in the latter, the coral shows an anterior view (figure 1B)
One might speculate how a Renaissance painter was able to represent the anatomic model so accurately. ${ }^{2} \mathrm{~A}$ reasonable possibility is that a wax cast of the bronchial tree was used. ${ }^{3}$ Another more intriguing possibility is that a readymade cast made from coagulate blood within the bronchial tree was available from a beheaded body. ${ }^{4}$ At that time, executed prisoners were often used for scientific study and preparation of anatomical specimens. Whatever the origin of the figurative model, I believe that the hypothesis of the bronchial tree as hidden anatomy in Piero della Francesca's coral pendants is plausible and worthy of attention.

Acknowledgements I would like to thank Professor Anna Lisa Rossetto for her help in translating this letter.

\section{Competing interests None.}

Provenance and peer review Not commissioned; internally peer reviewed.

\section{REFERENCES}

1 Vasari G. Le vite de'più eccellenti pittori, scultori ed architetti. Giunti Firenze, 1568.

2 Meshberger FL. An interpretation of Michelangelo's Creation of Adam based on neuroanatomy. JAMA 1990;264:1837-41.

3 Davies A. The evolution of bronchial casts. Med Hist 1973;17:386-91.

4 Neto MR, Hoffman S, Almeida FA. Unexpected bronchial anatomy lesson. Am J Resp Crit Care Med 2013;187:e7-8.

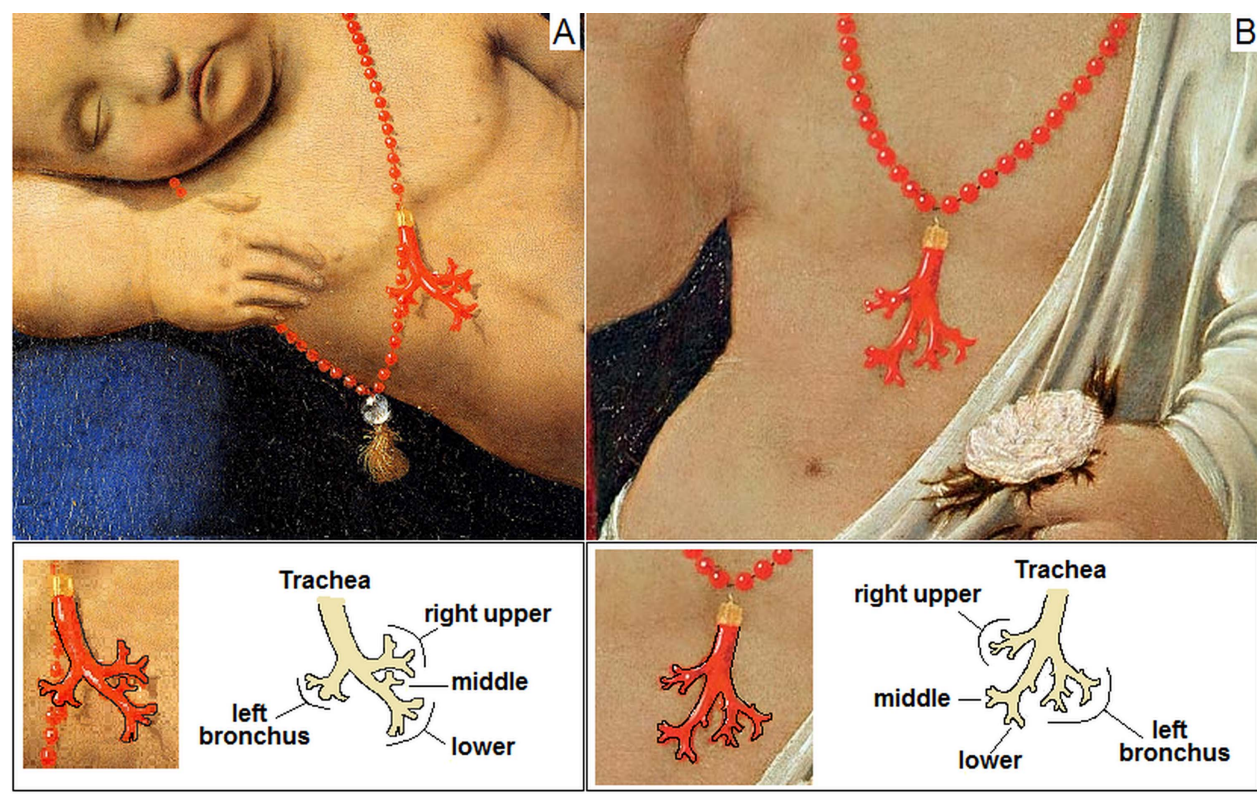

Figure 1 (A) The coral pendant (detail in the Pala Montefeltro). In the lower section the contour (right) and the drawing (left) of the hidden bronchial tree with nomenclature The Pala Montefeltro (1472-1474). Piero della Francesca. Pinacoteca di Brera, Milan. (B) The coral pendant (detail in the Madonna di Senigallia). In the lower section, the contour (right) and the drawing (left) of the hidden bronchial tree with nomenclature. The Madonna di Senigallia (1472-74). Piero della Francesca. Galleria Nazionale delle Marche, Urbino. 